\title{
Intervenciones psicosociales y sus efectos en la trayectoria de mujeres inmigradas en Chile
}

\section{Psychosocial Interventions and Their Effects on the Trajectory of Immigrant Women in Chile}

Recepción: 20 Mayo 2017 | Aprobación: 22 Agosto 2017

\author{
Caterine Galaz V.a \\ Universidad de Chile, Chile \\ ORCID: http://orcid.org/0000-0001-6301-7609 \\ Catalina Álvarez \\ Universidad de Chile, Chile \\ Luciana Hedrera \\ Universidad de Chile, Chile \\ Margarita María Becerra \\ Universidad de Chile, Chile
}

\footnotetext{
a Autora de correspondencia. Correo electrónico: cgalazvalderrama@uchile.cl

Para citar este artículo: Galaz, C., Álvarez, C., Hedrera, L., \& Becerra, M. M. (2017). Intervenciones psicosociales y sus efectos en la trayectoria de mujeres inmigradas en Chile. Universitas Psychologica, 16(5), 1-15. https://doi.org/10.11144/Javeriana.upsy16-5.ipet
}

\section{RESUMEN}

Parte de los análisis sobre las migraciones en Chile ponen su atención en los sujetos inmigrados y su nivel de inclusión en diferentes esferas sociales. Ante ello, giramos la mirada hacia la intervención psicosocial desde un enfoque feminista, observamos las formas de actuación de las intervenciones, cómo estas generan efectos psicosociales y las "líneas de fuga" (Deleuze \& Guattari, 1988/2012) que escapan a estas prácticas más hegemónicas. Para ello, se realizó un conjunto de Producciones Narrativas con interventoras y usuarias lo que, a través de un proceso de "figuración", posibilitó comprender los múltiples puentes de apertura, contradicción y cierre en las trayectorias de las mujeres inmigradas y su paso por servicios públicos y de la sociedad civil.

Palabras clave

inmigración; producciones narrativas; intervención psicosocial; género; inclusión social.

\footnotetext{
ABSTRACT

Part of the analysis on migration in Chile focuses on immigrant subjects and their level of inclusion in different social spheres. Therefore we turn our eyes towards psychosocial intervention: from a feminist perspective, we look at the ways interventions act and generate psychosocial effects and the "line of flight" (Deleuze \& Guattari, 1988/2012) that escapes hegemonic practices. For this, a set of Narrative Productions was carried out with interveners and users, which through a process of figuration, made it possible to understand the multiple bridges of opening, closure and contradiction that overlap in the trajectories of immigrant women and their passage through civil and public services.

Keywords

immigration; narrative productions; psychosocial intervention; gender; social inclusion.
} 
La situación mundial se caracteriza por cambios culturales y económicos, producto de transformaciones globales y locales, ligadas a la transnacionalización de la producción económica (Mora, 2008; Benhabib \& Resnik, 2009) con la consecuente movilidad humana vinculada a dicha producción. $\mathrm{Al}$ respecto se ha calculado que el $3.2 \%$ de la población vive en países que no son el de su origen, lo que representa 214 millones de personas (Organización Internacional de las Migraciones [OIM], 2015). El exponencial incremento de movimientos poblacionales dentro de Latinoamérica y el liderazgo de las mujeres en estos flujos migratorios han ido modificando significativamente los escenarios sociales de esta región (Echeverri, Pedone, \& Gil, 2013). La realidad en Chile no es ajena a esta situación, y desde los años noventa se ha vuelto horizonte de instalación para personas provenientes de países latinoamericanos y de Centro América, atraídas por su estabilidad y crecimiento económico y político (Matus, Cortez, Hemansen, Sabatini, \& Silva, 2012; Tijoux, 2011). Según datos oficiales, Chile dispondría de unas 420 mil personas inmigradas, menos del $2.6 \%$ de la población, observándose una clara tendencia a la feminización (Departamento de Extranjería y Migración [DEM], 2016). Para algunas autoras latinoamericanas, en estos procesos de instalación se presenta una doble exclusión de las mujeres inmigradas: en tanto su condición de extranjeras y su condición de género $^{\mathrm{i}}$

(Gil Araujo, 2006; Stefoni, 2011). En cuanto a las características de los colectivos inmigrantes en Chile, se puede señalar que, en su mayoría, provienen de los países de la región, particularmente de Perú (33.3\%), Argentina (15\%) y Colombia (13.8\%). Casi un $80 \%$ proviene de América Latina (Ministerio de Desarrollo Social, 2015), sumado a un aumento progresivo reciente de población de origen haitiano (Rojas, Amode, \& Vázquez, 2016).

La homogenización ha sido la lógica de funcionamiento de diversas políticas públicas respecto de la extranjería en la región, para consolidar la construcción de una "ciudadanía tipo" dentro de la comunidad social, normativizando otras identificaciones que se alejaran de este ideal nacional (Paredes, 2008). En el caso chileno, la "asimilación" ha sido la tónica de las diversas actuaciones públicas (Poblete \& Galaz, 2007).

Según Galaz, Poblete y Frías (2015), se evidencia que existen dificultades para el acceso igualitario a la oferta programática en vivienda, salud, trabajo y educación, sumadas a condiciones precarias de tipo estructural. Ante muchas de las necesidades legales, formativas y de orientación social, se ha desarrollado en los últimos años un conjunto de organizaciones que trabajan con población inmigrante a nivel local: el Instituto Católico de las Migraciones (INCAMI), el Servicio Jesuita Migrante (SJM), oficinas específicas de municipios con mayor población extranjera, clínicas jurídicas de universidades y otras organizaciones seculares de la sociedad civil que constituyen un tejido dedicado a la promoción psicosocial de la población inmigrada, principalmente orientadas a la atención legal y la inserción sociolaboral.

Es en este ámbito de intervención donde se centró el interés analítico de esta investigación, buscando comprender desde un enfoque cualitativo, las dinámicas de inclusión social y los efectos de subjetivación producidas por el dispositivo de intervención social por el que transitan las mujeres inmigradas. Desde la construcción de "figuraciones" a partir de Producciones Narrativas, este artículo aborda la forma en que las interventoras entienden su espacio de acción, junto con los efectos que esto tiene en las trayectorias de las mujeres inmigradas, buscando comprender las reproducciones, transformaciones y puntos de fuga que estas estrategias posibilitan. El artículo permite mostrar de qué modo actúan diversas categorías de desigualdad y jerarquía (género, nacionalidad, clase social, estatus jurídico) junto a los paradigmas que subyacen a las intervenciones que desarrollan las profesionales. 


\section{Perspectiva teórica y metodología}

El fenómeno migratorio a nivel internacional, en relación con la conformación identitaria grupal, ha generado aspectos paradójicos que fluctúan entre la fascinación y el rechazo por parte de la comunidad de instalación y entre el deseo de adaptarse y el temor a perderse por la población inmigrada (Galaz, 2009), a través de diversos procesos de subjetivación (Berlivet, 2013).

En esta relación social emerge la "diferencia" (Brah, 1987), la cual se construye en un contexto sociohistórico particular, en una relación situacional y supone algo/alguien que la define como tal. En ese sentido, emerge la categoría social de "inmigrante" en una relación concreta macro y microestructural, vinculada a conceptos como el de Estado-nación, cultura, pertenencia grupal, identidad-alteridad, entre otros (Echeverri, 2016; Romero, 2003; Tijoux, 2011; Yuval-Davis, 2004). De esta manera, las diferencias son relacionales y no sustantivas: no están esencialmente en el "sujeto diferenciado", sino en la relación que se establece y en las dinámicas de poder y resistencia que de esta se derivan (Brah, 1987; Montenegro, Galaz, Yufra, \& Montenegro, 2011), enmarcada en sistemas de control. La relación entre el sujeto inmigrado y los miembros de la sociedad de instalación se encuentra entramada en relaciones de poder desiguales, lo que hace que se configuren unos/ as otros/as situados como totalmente diferentes, y en algunos casos, como "deficientes" en relación con el pensamiento hegemónico (Galaz \& Yufra, 2016). No se trata de una diferencia como una construcción aséptica que señala una distinción entre exo y endogrupo (nacional/extranjera), sino que nos encontramos con una diferencia "jerarquizada" entre unas y otras, es decir, un problema relacionado con la "posicionalidad" y la asimetría (Anthias, 2002).

El campo de la intervención psicosocial, por tanto, funcionaría como un engranaje más dentro de este paradigma de poder en las relaciones sociales ya que, a través de ella, se estructuran conocimientos y técnicas expertas. Las narrativas de las intervenciones sociales, así como las políticas públicas a las cuales responden, "generan clasificaciones y distinciones entre poblaciones, construyendo a las personas en tanto que sujetos y objetos de las mismas, regulando sus vidas e inventando significados sobre los grupos a los que quedamos vinculados, o por oposición, excluidos" (Agrela, 2006, p. 5). En este afán de privilegiar un eje de constitución de diferencia, se visualiza un espacio de colonialidad (Mignolo, 2003; Paredes, 2008; Quijano, 2000; Said, 2003), ya que esencializa a los sujetos a partir de una única adscripción, posibilitando dispositivos materiales y simbólicos de expansionismo y subordinación de ciertos grupos sobre otros.

Vemos que estas dinámicas de poder norman la sociedad en función de ejes diferenciadores socialmente construidos como el género, la raza, la clase, la edad, regulando aspectos de la vida social en pos de determinadas jerarquías sociales (Crenshaw, 1989; Salem, 2014). Así, la forma en que tanto las interventoras como las mujeres inmigradas son concebidas por los dispositivos determina las estrategias de intervención y las posibilidades de atención que pueden darse en los servicios sociales disponibles para ellas (Liberona, 2012).

\section{Marco metodológico}

En esta reflexión nos situamos desde una posición de investigación situada (Haraway, 1991), con una visión hermenéuticainterpretativa (Gadamer, 1994). Entenderemos el proceso de investigación desde una lógica dialógica y de interpelación constante y mutua entre investigadoras y participantes, cuestionando la noción positivista que divide al objeto del sujeto de investigación, como también al lugar y el tiempo de los hechos, del lugar y tiempo de análisis (Balasch \& Montenegro, 2003). Siguiendo a Haraway (1991), el conocimiento se produce a partir de "conexiones parciales" entre las posiciones materiales y semióticas de los sujetos involucrados. Siendo coherente con estos principios epistemológicos, esta investigación se centró en la producción narrativa de acontecimientos de las participantes inmersas en los circuitos de 
intervención psicosocial. Balasch y Montenegro (2003) promueven un tipo de investigación donde se elaboran relatos a partir de sesiones de trabajo donde las investigadoras y las participantes reflexionan conjuntamente. La información obtenida fue utilizada para escribir una narración preliminar, la que luego se reelaboró constantemente con la participación activa de las integrantes hasta llegar a una versión definitiva, superando la clásica transcripción de datos. Este tipo de técnica de investigación busca promover "la agencia de las participantes al disponer de la posibilidad de agregar correcciones y modificaciones al texto" (Balasch \& Montenegro, 2003, p. 47).

Para esta investigación se llevaron a cabo ocho Producciones Narrativas (cuatro con interventoras sociales ubicadas en diferentes espacios públicos y de la sociedad civil y cuatro con mujeres inmigradas de diferente nacionalidad que habían transitado por diversas intervenciones sociales). La muestra fue de carácter intencionado: se intentó mostrar el máximo de variabilidad en los tipos de servicios, tanto públicos como de la sociedad civil, como también acudir a mujeres de diferentes edades y procedencias nacionales. Cada Producción Narrativa consideró entre tres a cinco encuentros de diálogo con las participantes, y significó el desarrollo de productos lingüísticos que se fueron perfeccionando en análisis a medida que se sostuvieron en cada una de las sesiones.

\section{Discusión: La zigzagueante e inacabada construcción de puentes}

Para el siguiente análisis se presentan algunas "figuraciones" construidas a partir de las Producciones Narrativas, las que, siguiendo a De Lauretis (2007), pueden ser entendidas como narraciones epistémico-políticas que permiten dar una explicación de un proceso a través de un ícono. Estas figuraciones no pretenden generar nuevas categorías estancas o estandarizar ciertas terminologías, sino más bien generar narraciones diversas que posibiliten lecturas sobre procesos que siempre son complejos, como pueden ser las intervenciones psicosociales con mujeres inmigradas. Nuestra intención es presentar estas figuraciones porque su lectura permite una interferencia sobre narraciones habituales que se dan respecto del afán transformador de la intervención. La figuración matriz que proponemos es la figura del "puente", de la cual se desprende el análisis sobre las acciones de intervención y las diferentes posiciones de subjetivación que de ellas emergen.

La figura del puente: construcción permanente de las mujeres inmigradas

A diferencia de otros proyectos migratorios, nunca tuve expectativas ni objetivos premeditados, sino que las mismas experiencias fueron construyendo este camino. Cada persona o grupo que migra, tiene una historia con sus particularidades, pero hay aspectos en común que compartimos las mujeres aquí. Lo cierto es que, todas experimentamos un fuerte desarraigo de nuestros núcleos personales y familiares, y también un desapego con nuestro entorno colectivo y social. Las mujeres inmigrantes tenemos que hacernos cargo de todo lo que traemos, pero también de todo lo que nos encontramos. (PN Mujer inmigrada 2, 2016: 3)

A través del proceso narrativo vemos que los movimientos migratorios se despliegan por medio de múltiples rutas y patrones, los cuales ponen en tensión las formas en que comprendemos la inclusión social, al evidenciar diferencias en el acceso a diversos ámbitos sociales, políticos y económicos tanto en los países de origen como en los de destino. La idea de movimiento que subyace al ejercicio de migrar es algo recurrente, expresando sus experiencias de intervención, sus experiencias migratorias y procesos de inclusión a través de la construcción de uno o más puentes. Así, la figura del puente no aparece como una categoría fija, estable y definida, sino como una figura escurridiza y en permanente construcción (Anzaldúa, 2001).

Vemos en las Producciones Narrativas que la trayectoria migratoria comienza en la confluencia de distintas necesidades y deseos: mejores oportunidades económicas, protección 
nte situaciones de violencia, presiones familiares o de pareja, búsqueda de refugio político, anhelo de nuevas formas de vida, establecimiento de vínculos afectivos, entre otros. Ciertos puentes comenzarán más arraigados en las situaciones de vulnerabilidad y violencia (económica, laboral, política, afectiva, etc.) -desde donde primariamente la intervención psicosocial se sitúa-, apareciendo la decisión de migrar como una posible vía de escape. Pero a la vez, están cruzados por el anhelo de transformar sus proyectos de vida, siendo construidos a partir de decisiones que se reivindican como propias y que revelan aspectos agenciadores de las mujeres. Son puentes que emergen más allá de lo económico y social, pasando a territorios como el deseo: ganas de reinventarse, de probar nuevas formas de vivir y mejorar su calidad de vida en distintas esferas (PN Mujer migrada, 2016).

Los puentes que se narran pueden ser construidos entre distintas riberas: entre el país de destino y el de llegada; hacia la inclusión en distintos ámbitos de la sociedad chilena (laboral, económico, político, educativo) y también entre personas e instituciones. En esta diversidad, algo que es transversal y que hace tan atractiva la figura del puente como guía del análisis, es la constante posibilidad de construcción, reconstrucción y transformación de viejos y nuevos caminos en distintos sentidos (Mezzadra, 2007), enfrentándose a la imagen lineal y progresiva que prevalece en las narrativas de interventoras sociales sobre la inclusión social de la población inmigrada.

Los puentes que construyen las mujeres inmigradas pueden ser imaginados como la escalera infinita de Escher: desembocando los unos en los otros en diferentes direcciones, pero que a diferencia de esta célebre figura, siempre implican la posibilidad de hacer o deshacer otros. Veremos en el análisis que estos puentes son construidos, habitados y transitados por distintos sujetos, quienes, a la vez, son construidos por el devenir mismo del puente. Es decir, los sujetos no se sitúan fuera, sino que son parte y arte del mismo.
Las figuras de la intervención social con mujeres inmigradas

Agrela (2004) reflexiona sobre cómo las políticas públicas construyen a la mujer inmigrada como un sujeto de intervención psicosocial y cómo se explicitan algunos modelos que resumen las prácticas de integración por las que cruza este colectivo. Coincidiendo con esta perspectiva crítica, construimos algunas figuraciones sobre la intervención social para evidenciar las reflexiones que se desarrollaron entre las investigadoras y algunas interventoras sociales y que muestran una visión crítica de sus propios posicionamientos cotidianos, un descentramiento político y personal sobre sus acciones y los efectos que estas tienen en las mujeres (Aguirre, 2012). Estas figuraciones no tienen el afán de dar una mirada reductiva de lo que pasa en esos espacios de intermediación ni tampoco son modelos que son puestos en prácticas de manera unívoca, sino más bien buscan evidenciar la complejidad de los procesos de atención en que incurren las profesionales dentro de los dispositivos de intervención social.

\section{Puentes con andamiajes asistencialistas}

Existen políticas de género, pero cuando aparecen las mujeres inmigradas, se les ve como "pobrecitas", "necesitadas", "víctimas", sin considerar el potencial que muchas veces tienen, tanto de sus experiencias pre-migratorias como en su camino de inserción en este nuevo contexto. Las mujeres siguen apareciendo en un discurso asistencialista: te vamos atender, te vamos a apoyar, te vamos a ayudar. Y en el otro lado, las propias mujeres inmigradas ven en algunas atenciones sociales que si no te victimizas, no te atenderán. Se vuelve perverso ese círculo asistencialista. En el Estado está acentuada esta idea de calificación socioeconómica para visualizar si encaja como "sujeto vulnerable" o no, para darles unos beneficios determinados, sin llegar a una visión crítica de por qué se generan esas condiciones de vulnerabilidad, de cómo el mismo sistema vuelve vulnerables a estas personas. (PN interventora 4, 2016: 3) 
Históricamente, se puede señalar que, dentro de los sistemas de intervención psicosocial en Chile, una de las lógicas de actuación que ha prevalecido y fue acentuada en dictadura es el asistencialismo (Raczynski, 2002) y la entrega de beneficios directos a ciertos colectivos en situación de desventaja, que son considerados como "necesitados", "incapacitados", "víctimas" (Galaz \& Guarderas, 2016).

Esta es una de las matrices que sigue operando junto a otros modelos en las políticas públicas y es uno de los sistemas psicosociales con los que se encuentran las mujeres inmigradas cuando atraviesan diversos espacios públicos y privados. Sin embargo, la reflexión que hacen algunas interventoras es que esta matriz asistencialista muchas veces se intensifica en la catalogación de "mujer inmigrada vulnerable". En esa conjunción de factores, ya no solo opera la diferenciación económica y de saberes entre interventoraintervenida (Montenegro, 2001), sino también la de género y la de la procedencia nacional, lo que suma la mirada colonialista al asistencialismo de la intervención.

Los andamiajes del puente se vuelven asistencialistas cuando se plantea una intervención que solo entrega recursos directos a las mujeres inmigradas, descansando en el discurso de que ante la emergencia "es lo que se puede hacer" (PN Interventora 3, 2016: 4). Así también, el asistencialismo se produce cuando las relaciones de poder/saber entre interventora e intervenida fijan la responsabilidad del cambio en el "conocimiento experto", concibiendo a las mujeres que pasan por los servicios como sujetos sin capacidades para transformar la situación que las complica, siendo únicamente objeto de las decisiones de los profesionales y su autoridad (PN, interventora 2, 2016). Como veremos más adelante, este puente asistencialista que emerge como rémora en las intervenciones ubica a las mujeres inmigradas en una posición "victimizada", de sujeto que requiere ser categorizada bajo ciertas lógicas de afectación para que cumpla los estándares de atención vinculados a la provisión de recursos directos.

\section{Puentes con andamiajes mesiánicos}

\begin{abstract}
Algunas llegan con roles de género muy marcados y el machismo es más visible. En el caso de las mujeres haitianas vienen de una sociedad de origen muy machista, incluso, la decisión de emigrar en algunos casos no ha sido tomada por ellas. Algunas son enviadas por sus familiares como proyecto común: ahorran dinero por mucho tiempo y sortean a quién le toca salir del país, quien es el más joven o quien tiene más posibilidades en el otro contexto de estudiar y trabajar. Otras mujeres, en tanto, son traídas por sus maridos...Ante esto, se nos remueve el piso como interventores/as porque ante una persona que no ha decidido por ella misma, ¿Qué podemos hacer? Pues removerlas.... Entonces la concienciación es lo básico. (PN, interventora 3, 2016: 16)
\end{abstract}

En algunos puentes, que en ocasiones las interventoras intentan levantar, emerge la idea de que las mujeres inmigradas están "apresadas" por diversos factores: el patriarcado, la clase, el etnocentrismo cultural, la falta de educación y cultura, entre otros. En esta consideración, la contraparte emerge con cierto cariz mesiánicoliberador ya que sitúa a las profesionales como agentes capaces de realizar una transformación en la vida de las otras mujeres -inmigradas-, pero también en el sistema social en general (PN, interventora 4: 8). Así, a través de la acción social que algunas interventoras desarrollan, se cree poder afectar las relaciones de género ya que se concibe que algunas inmigradas provienen de sociedades machistas - sin considerar que las desigualdades de género en el contexto chileno no son una arista superada-, o bien, a través de la acción social, pueden superar la situación de pobreza en la que se han ubicado en estos contextos. En esas lecturas, no solo se invisibilizan las condiciones estructurales del país que ubican a las mujeres inmigradas en ciertos espacios productivos y reproductivos, sino que además, posiciona la agencia en el lado de la intervención. Una interventora enfatiza que:

(...) es una preocupación que las intervenciones hacia inmigrados/as sean tan normativas. Les enseñamos habilidades parentales a los sectores 
pobres. Se da por supuesto que las personas en situación de pobreza no tienen esas habilidades y hay que enseñarles a ser madres y padres. Lo mismo a las personas extranjeras. (PN, Interventora 3, 2016: 8)

Puentes con andamiajes culturalizados y generizados

La crítica a la culturalización de los colectivos inmigrados y de los roles generizados de las mujeres inmigradas en algunas prácticas de intervención social está presente en la reflexión de algunas profesionales. Sin embargo, se destaca que en el día a día, emergen las imágenes de "mujer inmigrada" como un todo homogéneo marcado por "la cultura" de su marco de referencia, y como portadoras por excelencia de roles generizados. Como señalamos, la construcción de "diferencia" se relaciona con la posicionalidad y la asimetría (Anthias, 2002) existente entre el grupo de recepción-la comunidad chilena- y las personas inmigradas. Esta diferenciación asimétrica emerge en algunas prácticas concretas de algunas intervenciones y tiene ver con:

La asociación de respeto intercultural a la concreción folklorizada de hechos culturales (comidas típicas, fiestas, vestimentas, etc.);

La asociación entre prejuicios respecto de la nacionalidad y la ubicación laboral de estas mujeres (colombianas asociadas a un carácter amable y su vinculación laboral en atención de servicios, peruanas por su carácter dócil en labores de limpieza, etc.);

Y con el desarrollo de espacios especiales de atención ante la generalización de posiciones de género a todo un colectivo nacional (por ejemplo, el hecho de hacer talleres exclusivos para mujeres haitianas ante la idea de que su colectivo es machista y, por tanto, no asistirán si no poseen esas características). Así lo considera una profesional:

Y luego está el hecho que sobre algunas pesan muchas marcas. Se interseccionan, se superponen, se exageran. Son mujeres y negras y en una situación económica concreta. Tres

| Universitas Psychologica | V. I6 | No. 5 | 2017 | categorías que se articulan al unísono y que las ubica sólo en ciertos espacios sociales, los menos valorados. Es distinto ser haitiana que colombiana o dominicana, con o sin dinero. Sobre cada una pesan diversas etiquetas, se les asocia con diversas imágenes: colombianasprostitutas, haitiana-objeto sexual, peruananana, dominicana-trabajadora de peluquería. Desde estas etiquetas comienza a darse una segmentación laboral, independiente del capital cultural o educativo que traigan. Si se les categoriza de una manera, la intervención les encamina a ciertos nichos específicos laborales, donde la población chilena no quiere instalarse. Como si otro espacio no fuera posible. Las mujeres inmigradas acaban cuidando niños/ as, ancianos/as, hacen limpieza domiciliaria o industrial, trabajan en cafés con piernas, fuentes de soda, peluquerías, masajes y comercio sexual. (PN, Interventora 4, 2016, p. 3)

\section{Puentes con andamiajes liberales}

Algunas profesionales señalan que dentro de sus acciones se pueden denotar cómo a veces levantan puentes como agentes cooperadoras dentro de un sistema neoliberal de mercado como el chileno, ya que sus discursos y acciones resultan convergentes para que la ubicación psicosocial de las inmigradas se dé en los espacios socioeconómicos que el país financieramente requiere. Esto se da a través de las acciones de capacitación que se les brinda para poder acceder a ciertos nichos laborales disponibles (espacios de servicios y cuidados preferentemente). Parte de esta adaptación a la lógica del mercado termina ubicándolas también en espacios de subordinación y precarización socioeconómica (Galaz \& Yufra, 2016). Según emerge en las narrativas, el Estado tiende a desaparecer y la responsabilidad de la ubicación social y económica se torna individual.

Los cuerpos de las mujeres han sido fundamentales en la construcción de agendas y políticas nacionalistas donde los Estados han ensayado distintas intervenciones orientadas a controlar sus identidades (Yuval-Davis, 2004). En estas variadas estrategias, las mujeres inmigradas han sido incluidas como soportes 
de la economía y transmisoras de sus valores, afectando en ciertos modos de ser mujer, tal como se muestra en la siguiente cita:

La gente se vuelve pobre, y se siente pobre. Vemos que las personas extranjeras emergen como objeto de uso, de cambio, de mercancía más que de ser humano y eso tiene consecuencias en cómo algunas se sienten, cómo viven su experiencia migratoria, como se relacionan con el entorno. Mucha gente dice que no quiere pedir, y le da vergüenza. Pero está tan ahogada en problemas derivados de diversas circunstancias de instalación que no tiene otra posibilidad que acudir a solicitar apoyo... El estado a veces aparece como el gran ausente, y se les deja el deber de salir a la autogestión de ellas mismas. Entonces las intervenciones las ubican en esos espacios de trabajo que el resto de la sociedad no quiere. (PN, interventora 4, 2016: 4)

Algunas apuestas de intervención liberales subjetivizan a la mujer como "buena trabajadora" para el sistema, pero a su vez formulan un sujeto precarizado socioeconómicamente por su acceso a trabajos de baja calificación y con pocas posibilidades de ascenso social. Mora (2008) señala que existe una identificación de grupos inmigrados a ciertos colectivos de trabajo específico. De ahí que el trabajo sea una fuente de ingresos, pero también influya en la caracterización de las identidades de las mujeres inmigradas (Montenegro et al., 2011), reconociéndose a sí misma en un nuevo rol dentro la sociedad de instalación. Como telón de fondo, opera la idea de que la inmigración es un aporte, un hecho social rentable que puede favorecer a largo plazo a la comunidad chilena. Pero, además, la acción se justifica ante el beneficio economicista del grupo mayoritario nacional.

\section{Puentes con andamiajes agenciadores y críticos}

¿Por qué tenerle miedo al vínculo? Si tenemos posibilidad de formarlo a largo plazo, por qué no hacerlo. Somos interventoras y queremos transformar. Pero por qué no superar el límite de esta intervención, al menos con algunas de las mujeres que también quieren superar esa barrera. Es cierto que a veces partimos de un punto de inicio: algún proceso de regularización, alguna entrega de información puntual... pero esa mínima acción puede suponer también una posibilidad para poder cambiar nuestras relaciones a futuro. Superada la intervención, podemos alejarnos de la relación jerárquica entre profesional e inmigrada. (PN, interventora 3, 2016: 1)

La visión compartida que emerge de las producciones narrativas indica que cualquier tipo de intervención social en temas migratorios se plantea desde un carácter bastante complejo a nivel estructural, cruzado por diversos factores: por la ley migratoria vigente que fue desarrollada en dictadura y la consideración de la persona extranjera bajo la idea de control fronterizo; por el sistema neoliberal económico que promueve un carácter liberal en las actuaciones e impone límites a la acción estatal respecto de políticas públicas más universalistas para una mejor instalación social de las personas inmigradas; porque las medidas administrativas que se han ensayado desde lo público tienden a ser focalizadas y por tanto, deben determinarse diferentes perfiles de personas para poder ser atendidas; porque las actuaciones desde la sociedad civil han tendido a emerger desde entidades religiosas que comenzaron con asistencia directa -aunque algunas han derivado en actuaciones más agenciales- y porque sigue primando en la sociedad chilena, la visión monocultural donde las mujeres inmigradas emergen bajo categorías estancas y estereotipos respecto de sus colectivos de referencia nacional.

No obstante, las mujeres inmigradas y las interventoras pueden aventurar vías de fuga (Deleuze \& Guattari, 1988/2012), formas que escapan a las lógicas de las intervenciones más tradicionales; así, estas también pueden problematizar, posibilitar vías de agenciamiento y permitir nuevas articulaciones. De este modo, vemos participación y activismo de parte de las interventoras para el cambio de leyes y normativas, promoción de sistemas formativos donde se considere la trayectoria inicial educativa de las mujeres, negociación 
constante y sensibilización con el sistema privado para la contratación adecuada de este colectivo, entre otras.

Los efectos de los puentes en la construcción de subjetividades

Los efectos psicosociales que la intervención tiene son diversos y se relacionan con las diferenciaciones y categorizaciones antes señaladas. Se generan procesos de subjetivación o maneras en las que las personas se pueden narrar a sí mismas en el contexto de la sociedad de instalación (Foucault, 1999). La subjetivación se produce a partir de la experiencia, entendida como proceso de significación que es fruto de variadas y complejas relaciones de seres sociales (De Lauretis, 2007). Es a este tipo de efectos a los que queremos referirnos en el siguiente apartado: las condensaciones que generan ciertas formas de construcción de las mujeres inmigradas, a veces desde el ámbito social en general como desde la intervención social en particular.

\section{Mujeres víctimas y en falta}

¿Estas mujeres están en situación vulnerable. Muchas veces esta situación precaria ya la vivían en sus contextos de origen pero se reproduce con más dureza en Chile, sin tener una red de seguridad social mínima, sin redes interpersonales confiables, sin información clara de la institucionalidad nacional. La vulnerabilidad en estas mujeres, las dominicanas especialmente, está asentada desde la misma forma en que vinieron. Entrar por pasos fronterizos no habilitados a través de redes de tráfico que las deja en una situación tan compleja que la entrada a la prostitución es una vía de salida en algunos casos, o la única posible. Y no sólo en el comercio sexual, sino las deja a merced de precarias condiciones y malos trabajos en otros ámbitos. (Interventora 1, 2016: 13)

La constitución problemática de las trayectorias femeninas a través de las intervenciones permite cierta homogenización y normativización de las mujeres bajo una visión victimista (Cuvi \& Martínez, 1994), pero a la vez posibilita la estandarización de servicios bajo la retórica de la inclusión de género y entidad posibilitadora de derechos. La victimización la comprendemos como un proceso donde "la intervención genera ciertos mundos posibles de ser vividos por estas mujeres para poder ser incluidas en la rueda de estos dispositivos y por tanto, de la ciudadanía" (Galaz \& Guarderas, 2016, p. 12). En las producciones narrativas, algunas interventoras subjetivizan a la mujer inmigrada como "mujer víctima", por medio de argumentaciones que apelan a sus condiciones de vulnerabilidad, y a las múltiples violencias que viven, ya sea por los casos de violencia machista en las relaciones de pareja, por el abuso laboral, por desplazamientos precarios, por otros grupos dominantes nacionales, y la sociedad. Se enfatiza y se legitima la necesidad de especializar las intervenciones para que las mujeres inmigradas se adapten a formas de vida, especializando dichas intervenciones hacia el cuidado infantil, el trabajo sexual, la salud reproductiva, entre otros. En ese sentido, los efectos de la intervención psicosocial son formas de subjetivación, diferenciación y subalternización en dualidades: mujer-hombre, nacionalesinmigrantes, nosotros/as-ellos/as, interventor/ausuaria, basado en vínculos de saber-poder. Estas dinámicas sitúan a la "mujer inmigrante" como mujer-víctima y subalterna, ubicándola como una otra distinta y oprimida (Agrela, 2006; Mohanty, 1984; Spivak, 1988). Por otro lado, los puentes del sujeto victimizado se intersectan y son reforzados en la emergencia de la mujer inmigrada como "mujer en falta" (Montenegro et al., 2011).

En las narrativas, tanto mujeres inmigradas como interventoras construyen identitariamente a las mujeres inmigradas como carentes, necesitadas, con insuficiente información sobre sus derechos, propensas al auto-engaño, y la sobre-idealización del proyecto migratorio ante la idea de la migración como "promesa del cambio" (Véanse, Interventora 4, 2016; Mujer inmigrada 1 y 2, 2016). Pese a que se evidencian estos procesos de diferenciación y subalternización, estos son problematizados en 
algunas narrativas a partir de comprensiones críticas que dejan de esencializar a las mujeres desde estos lugares, evidenciando que son los contextos sociales y no algo intrínseco en ellas lo que las ubica en una situación de vulnerabilidad, como, por ejemplo, el desclasamiento social que viven al insertarse en labores menos calificadas de su nivel de estudio, dado a las dificultades existentes en materia migratoria en los procesos de instalación.

En este puente, las mujeres inmigradas son asumidas como un colectivo homogéneo agrupado por carencias y dependencias comunes que invisibilizan las especificidades que las intersectan (como la raza, género, clase social) (Mohanty, 1984), así como la capacidad de agencia de su colectivo. Las mujeres inmigradas al enunciarse a sí mismas desde esos lugares, reproducen posiciones donde el dispositivo las ubica, que le permiten transitar en el puente desde posiciones justificadas netamente por la intervención.

\section{Mujeres estratégicas y/o transgresoras o activistas}

Durante la fase de inserción, fui consciente de que ya no era solamente Sandra y su familia, Sandra mamá, sino que mis roles fueron ampliándose cuando empecé a desenvolverme en espacios fuera de la esfera nuclear y familiar. [...] De a poco, empecé a involucrarme en Chile con algunas personas [...] y de esta manera fui estableciendo contactos con organizaciones sociales y personas diversas. Fui conociendo y haciéndome conocer [...]. Lo más importante fue sentir que ya no estaba sola y que paulatinamente fui forjando relaciones más cercanas, conformando un grupo de redes sociales fundamentales para la inclusión en la sociedad en la que vivimos. (Mujer inmigrada 1, 2016: 3)

A veces los puentes se vuelven transgresores, reivindicando la agencia (Brah, 1987). Estos están compuestos de múltiples relaciones sociales de cooperación que son consideradas parte imprescindible del camino hacia la inclusión social. En este ejercicio de construcción, se desafían miedos y deseos colectivos, y se producen formas de significación identitaria que permiten la tensión de relaciones de poder. Se desafían las relaciones de género a partir de las mismas experiencias de migración ya que algunas mujeres adquieren nuevos roles a nivel familiar y social, pasando muchas veces de ser cuidadoras a ser sostenedoras económicas de sí mismas y de otros/as gracias a la inserción en ámbitos laborales. Esta sensación de independencia acompañada por la construcción de nuevas redes refuerza en estas mujeres la construcción de identidades con agencia, por medio de las cuales logran enfrentarse a las dificultades que acompañan el proceso de instalación. A veces, van desafiando las relaciones de poder presentes en los servicios de atención, a través de redes de asociatividad que funcionan además como espacio de difusión de información que permite exigir derechos (PN Mujer inmigrada 1, 2016).

Las interventoras que consideran la capacidad de agencia de las mujeres inmigradas en estos términos, crean un espacio de relación que permite la negociación de los objetivos y de las decisiones consecuentes, buscando la horizontalidad a través de la socialización de la información. Este puente, que reconoce las diferencias en pos de construir un nuevo espacio de acción mestizo (Anzaldúa, 1989), es narrado por aquellas mujeres que construyen experiencias de lucha y acción colectiva y que tensionan y resisten a los marcos normativos provenientes del Estado y al sistema patriarcal dominante en el ámbito de la acción política.

Para estar incluidos y hacer visibles nuestras demandas, siempre he pensado que la acción colectiva es fundamental para las transformaciones y en especial, para las que nos planteamos las mujeres frente al patriarcado. Yo desde joven he estado inserta en el ámbito, vinculada a organizaciones de mujeres y comprometida con el trabajo social. Siempre estamos haciendo política. Y cuando no lo hago me siento culpable, me incita a hacerlo de nuevo, es parte de mi activismo. (Mujer inmigrada 2, 2016: 14) 


\section{Conclusiones}

En este trabajo, las Producciones Narrativas nos ayudaron a establecer figuraciones que esbozan un análisis de las prácticas y discursos, y reflexionar sobre los efectos de esas consideraciones sobre sus sujetos de atención -mujeres intervenidas-. En algunas figuraciones, se evidencia una cierta supremacía del conocimiento experto -la llamada dupla psicosocial- por sobre otros tipos de conocimiento, generando diálogos asimétricos entre los/as profesionales y las mujeres que son atendidas, lo que a su vez se basa en la legitimación de las capacidades teóricas, técnicas y profesionales como puntos de partida para tomar acciones sobre las vidas de aquellos/as considerados/as en una posición de desventaja. Se reproducen visiones dicotómicas de "nosotros/as" y "ellos/as" (mujerhombre, autóctona-inmigrante, interventoraintervenida), construyendo sujetos homogéneos en términos de agencia, clase y género (Jacobson, 2009). Estas clasificaciones y definiciones afectan la manera en que las mujeres se piensan y enuncian a sí mismas, apropiándose de ellas en algunos casos, pero en otros, negociándolas o resistiéndolas, tal como dan cuenta las producciones narrativas elaboradas en esta investigación.

La posición y asimetría en las relaciones por las que cruzan las mujeres inmigradas dentro de la intervención, invisibiliza otros ejes de diferenciación: en el caso de las mujeres inmigradas -incluso cuando en las prácticas existe un afán de reconocimiento social- al privilegiar por ejemplo la pertenencia étnico-nacional o bien el género, a veces se deja al margen el posicionamiento económico de estas mujeres. $O$ al contrario, se da prelación exclusivamente a la relación de clase, dejando en un segundo orden, otras posiciones de sujeto que complejizan su situación de dominación y agencia en el juego de otras intersecciones (Platero, 2014). Así, vemos que algunas actuaciones sociales se levantan o bien culturalizadas o generizadas o estratificadas por clase, privilegiando un único vector diferenciador.

Desde una lectura crítica de los sistemas de intervención social, vemos que las mujeres inmigradas serán consideradas más o menos alejadas de lo que es considerado el centro/ normalidad -lo nacional chileno-, motivo por el cual se justifica, constantemente y de manera sutil, la intervención sobre ellas y sus trayectorias, muchas veces en términos civilizatorios ya que será preciso "liberarlas" de ciertas cargas culturales (Montenegro et al., 2011). Mientras tanto, las mujeres inmigradas que emergen como "objetos" de intervención, desarrollan diversas formas de adaptación, sometimiento, crítica o rechazo sobre esas posibles dominaciones. Muchas veces estos posicionamientos resultan estratégicos, precisamente con el fin de posibilitarse a sí mismas mejores condiciones de instalación.

La figuración de "puentes" permite evidenciar que las mujeres inmigradas construyen sus devenires de manera compleja, y muchas veces de forma distinta a los que las interventoras buscan construir para ellas, siendo procesos negociados y dinámicos, en los cuales se va afectando el destino, la dirección y el ensamblaje de dichos puentes. Así bien, los puentes construidos no emergen como un espacio de tránsito unidireccional, determinado por la intervención, sino un proceso donde los sujetos pueden estar en el puente, vivir y apropiarse de él como un espacio de acción, o también pueden desecharlo y sobre él construir nuevos. Para Anzaldúa (2001), esta posibilidad de construir un puente con otros/as siempre significa un riesgo, en tanto implica abrir un portal desde un espacio de comodidad hacia uno de inseguridad, el que, sin embargo, también permite la construcción de diferentes comunidades a partir de ciertas identificaciones parciales. A la luz de nuestro análisis, se da cuenta que son este tipo de puentes los más relevantes para interventoras y mujeres inmigradas: aquellos donde el vínculo, la negociación y la agencia contextualizada se vuelven motores de la intervención social. 


\section{Agradecimientos}

Este artículo recoge resultados de la investigación de carácter cualitativo "Intervención social con mujeres inmigradas: Reconocimiento, incorporación sociocultural e igualdad de oportunidades para la inclusión"; con el apoyo de la Vicerrectoría de Investigación y Desarrollo (VID) de la Universidad de Chile.

\section{Referencias}

Agrela, B. (2004). La acción social y las mujeres inmigrantes: ihacia unos modelos de intervención? Portularia, 4, 31-42. Recuperado de http://rabida.uhu.es/dspace/bitstream/h andle/10272/170/b15124794.pdf?sequence $=1$

Agrela, B. (2006). De los significados de género e inmigración (re)producidos en las políticas sociales y sus consecuencias para la acción e integración social. Migrations and Social Policies in Europe. Sesión de Trabajo, Universidad Pública de Navarra, Pamplona.

Aguirre, A. (2012). Figuras performativas de la acción colectiva. Una trayectoria con la Comisión Civil Internacional de Observación por los Derechos Humanos, desde las políticas de conocimiento feminista y la etnografía crítica (Tesis doctoral inédita). Universidad Autónoma de Barcelona, Barcelona.

Anthias, F. (2002). Género, etnicidad, clase y migración: inteseccionalidad y pertenencia transnacional. En F. Anthias \& P. Rodríguez (Eds.), Feminismos periféricos: discutiendo las categoría sexo, clase y raza (y etnicidad) con Floya Anthias (pp. 49-68). Granada: Alhulia.

Anzaldúa, G. (2001). Preface: (Un)natural bridges, (Un)safe spaces. En G. Anzaldúa \& A. Keating (Eds.), This bridge we call home (pp. 1-5). Nueva York: Routledge.

Anzaldúa, G. (1989). Hablar en lenguas: una carta a escritoras tercermundistas. En C. Moraga \& A. Castillo (Eds.), Esta puente, mi espalda (pp. 219-228). San Francisco, USA: Editorial "ismo".

Balasch, M., \& Montenegro, M. (2003). Una propuesta metodológica desde la epistemología de los conocimientos situados: las producciones narrativas. Encuentros en Psicología Social, 1(3), 44-48. Recuperado de https://s3.amazonaws.com/academia.ed u.documents/31561893/Balasch_M_Mont enegro M 2003 ... propuesta metodolog ica_desde_la_epis.pdf

Benhabib, S., \& Resnik, J. (2009). Introduction: Citizenship and migration theory engendered. En S. Benhabib \& J. Resnik (Eds.), Migatrions and mobilities: Citizenship, borders, and gender (pp. 1-45). Nueva York: New York University Press.

Berlivet, L. (2013). Les ressorts de la "biopolitique": "dispositifs de sécurité" et processus de "subjectivation" au prisme de l'histoire de la santé. Revue d'histoire Moderne et Contemporaine, 4(60-4/4 bis), 97-121. https://doi.org/10.3917/ rhmc.604.0097

Brah, A. (1987). Diferencia, diversidad y diferenciación. En B. Hook et al., Otras inapropiables. Feminismo desde las fronteras (pp. 71-80). Madrid: Traficantes de Sueños.

Butler, J. (2002). Cuerpos que importan: sobre los límites materiales y discursivos del "sexo". Buenos Aires: Paidós.

Butler, J. (2007). El género en disputa: El feminismo y la subversión de la identidad. Barcelona: Paidós.

Crenshaw, K. (1989). Demarginalizing the intersection of race and sex: A black feminist critique of antidiscrimination doctrine, feminist theory and antiracist politics. Chicago: University of Chicago Legal Forum.

Cuvi, M., \& Martínez, A. (1994). El muro interior. Quito: CEPLAES-ABYA YALA.

Chile, Departamento de Extranjería y Migración [DEM] (2016). Estadísticas migratorias 2005-2015. Santiago: Autor. Recuperado de http://www.extranjeria.gob.cl/estadistic as-migratorias/ 
Chile, Ministerio de Desarrollo Social. (2015). Encuesta de Caracterización Socioeconómica Nacional CASEN 2013. Inmigrantes (Síntesis de resultados). Santiago: Autor. http://observatorio.minist eriodesarrollosocial.gob.cl/documentos/CA SEN_2013_Inmigrantes_revisada.pdf

De Lauretis, T. (2007). Figures of resistance. Essays in feminist theory. Illinois: Chicago Press.

Deleuze, G., \& Guattari, F. (2012). Mil mesetas. Capitalismo y esquizofrenia. Valencia: Pretextos.

Echeverri, M. (2016). Otredad racializada en la migración forzada de afrocolombianos a Antofagasta (Chile). Nómadas, 45, 91-103. Recuperado de http://www.redalyc.org/pdf/ 1051/105149483008.pdf

Echeverri, M., Pedone, C., \& Gil, S. (2013). "Entre la estigmatización y la restricción". Políticas migratorias y discursos políticos sobre familia, migración, género y generación en países de inmigración y emigración: España y Colombia. Palobra, 13(13), 84-107. Recuperado de http://revistas.unicartagena.edu.co/inde x.php/palobra/article/view/77

Foucault, M. (1999). La gubernamentalidad. En Obras Esenciales. Vol. 3: Estética, ética y herméutica (pp. 175-187). Barcelona: Paidós.

Galaz, C. (2009). Las relaciones de cooperación y exclusión entre personas con referentes socioculturales diversos. Un estudio sobre la alteridad (Tesis doctoral no publicada). Universidad Autónoma de Barcelona. Recuperado de http://www.tdx.cat/bitstrea $\mathrm{m} /$ handle/10803/5288/cgv1de1.pdf

Galaz, C. \& Guarderas, P. (2016) La intervención psicosocial y la construcción de las "mujeres víctimas". Una aproximación desde las experiencias de Quito (Ecuador) y Santiago (Chile). Revista de Estudios Sociales, 59, 68-82.

Galaz, C., Poblete, R., \& Frías, C. (2015). Inmigrantes en Chile: oferta programática, participación, inclusión y vulnerabilidad (ID.730566-23-LE14.
Publicación restringida). Santiago: Ministerio de Desarrollo Social.

Galaz, C., \& Yufra, L. (2016). Diferencias, jerarquías, subalternidad: discursos y prácticas de intervención hacia mujeres inmigradas [58 párrafos]. Forum: Qualitative Social Research, 17(3). Recuperado de http://www.qualitative-research.net/ind ex.php/fqs/article/viewFile/2379/4030

Gadamer, H. G. (1994). Verdad y método (2.a. ed). Salamanca: Sígueme.

Gil Araujo, S. (2006). Periféricos a la conquista de la metrópolis. Panorámica sobre las (in)migraciones latinoamericanas en España. Revista Estudios Migratorios Latinoamericanos, 20(60), 291-342.

Haraway, D. (1991). Ciencia, cyborgs y mujeres. La reinvención de la naturaleza. Madrid: Ediciones Cátedra.

Jacobson, D. (2009). Multiculturalism, gender and rights. En S. Benhabib \& J. Resnik (Eds.), Migatrions and mobilities. Citizenship, borders, and gender (pp. 304-332). Nueva York: New York University Press.

Liberona, N. (2012). De la alterisación a la discriminación en un sistema público de salud en crisis: conflictos interétnicos a propósito de la inmigración sudamericana en Chile. Revista Ciencias Sociales, 28, 31-38. Recuperado de http://www.redalyc. org/articulo.oa? $\mathrm{id}=70824554002$

Matus, T., Cortez-Monroy, F., Hermansen, P., Sabatini, F., \& Silva, C. (2012). Migración y municipios. Construcción de una propuesta de política pública de gestión municipal para la población inmigrante. Santiago: Centro de Políticas Públicas. Universidad Católica de Chile. Recuperado de http://politicaspublicas.uc.cl/wp-conten t/uploads/2015/02/propuestas-para-chile-2 012-capitulo-x.pdf

Mezzadra, S. (2007). Confini, migrazzioni, cittadinanza [Fronteras, migración y ciudadanía]. PAPERS, Revista de Sociologia, 85, 31-41. Recuperado de http://www.raco. cat/index.php/Papers/article/view/74159

Mignolo, W. (2003). Los estudios culturales: geopolíticas del conocimiento y exigencias 
institucionales. Revista Iberoamericana, 203 (69), 401-416. Recuperado de http://eva.universidad.edu.uy/pluginfile. php/175049/mod_resource/content/0/Mig nolo._Estudios_Culturales.pdf

Mohanty, Ch. (1984). Under Western eyes: Feminist scholarship and colonial discourses. boundary 2, 12(3), 333-358. Recuperado de http://weldd.org/sites/defau lt/files/Mohanty_Under_Western_Eyes_24 0914.pdf

Montenegro, M. (2001). Conocimientos, agentes y articulaciones. Una mirada situada a la intervención social. Athenea Digital. Recuperado de http://atheneadigital.net/ar ticle/view/n0-montenegro/17-html-es

Montenegro, M., Galaz, C., Yufra, L., \& Montenegro, K. (2011). Dinámicas de subjetivación y diferenciación en servicios sociales para mujeres inmigradas en la ciudad de Barcelona. Athenea Digital, 11(2), 113-132. Recuperado de http://www.redaly c.org/html/537/53719732008/

Mora, C. (2008). Globalización, género y migraciones. Revista Polis, 7(20), 285-297. https://doi.org/10.4067/ S0718-65682008000100015

Organización Internacional de las Migraciones (2015). Marco de Gobernanza sobre la migración. Elementos esenciales para facilitar la migración y la movilidad de manera ordenada, segura, regular y responsable gracias a políticas migratorias planificadas y bien gestionada. Recuperado de https://governingbodies.iom.int/es/syste $\mathrm{m} /$ files/es/council/106/C-106-40-Marco-de -Gobernanza-sobre-la-Migración.pdf

Paredes, J. (2008). Hilando fino desde el feminismo comunitario. La Paz, Bolivia: Comunidad Mujeres Creando Comunidad y CEDEC.

Platero, R. (2014). Metáforas y articulaciones para una pedagogía crítica sobre la interseccionalidad. Quaderns de Psicologia, 16(1), 55-72. https://doi.org/10.5565/rev/ qpsicologia. 1219

Poblete, R., \& Galaz, C. (2007). La identidad en la encrucijada: migración peruana y educación en el Chile de hoy. EMIGRA,
Working Paper, No. 3. Recuperado de https://ddd.uab.cat/pub/emigrawp/emigr awp_a2007n3/emigrawp_a2007n3p1.pdf

Quijano, A. (2000). Colonialidad del poder, eurocentrismo y América Latina. En E. Lander (Comp.), La colonialidad del saber: eurocentrismo y ciencias sociales. Perspectivas Latinoamericanas, p. 246. Buenos Aires: Consejo Latinoamericano de Ciencias Sociales. Recuperado de http://bibliotecavirtual.clacso.org.ar/ar/1 ibros/lander/quijano.rtf

Raczynski, D. (2002). Políticas sociales en los años noventa en Chile. Balance y desafíos. En P. Drake \& I. Jaksic (Comps.), El modelo chileno: democracia y desarrollo en los noventa (pp. 125-154). Santiago de Chile: LOM Ediciones.

Rojas, N., Amode, N., \& Va\#squez, J. (2016). Racismo y matrices de "inclusio\#n" de la migracio\# $\mathrm{n}$ haitiana en Chile: elementos conceptuales y contextuales para la discusio\#n. Polis, Revista Latinoamericana, 14(42), 217-245. https://doi.org/10.4067/ S0718-65682015000300011

Romero, C. (2003). Los desplazamientos de la "raza": de una invención política y la materialidad de sus efectos. Política y Sociedad, 40(1), 111-128. Recuperado de https://dialnet.unirioja.es/servlet/articul o? codigo $=765904$

Said, E. (2003). Orientalismo. Barcelona: De Bolsillo.

Salem, S. (2014). Feminismo isla\#mico, interseccionalidad y decolonialidad. Revista Tábula Rasa, 21, 111-122. Recuperado de http://www.scielo.org.co/pdf/tara/n21/n 21a06.pdf

Scott, J. (2011). Género: ¿Todavía una categoría útil para el análisis? La Manzana de la Discordia, 6(1), 95-101. Recuperado de http ://manzanadiscordia.univalle.edu.co/index. php/la_manzana_de_la_discordia/article/vi ew/1514/pdf

Spivak, G. (1988). Can the subaltern speak? En M. Nelson \& L. Grossberg (Eds.), Marxism and the interpretation of culture (pp. 271-313). Urbana: University of Illinoiss 
Press. Recuperado de http://abahlali.org/fil es/Can_the_subaltern_speak.pdf

Stefoni, C. (2015). Ley y política migratoria en Chile. La ambivalencia en la comprensión del migrante. En B. Feldman-Bianco, L. Rivera, C. Stefoni \& M. I. Villa (Comps.), La construcción social del sujeto migrante en América Latina: prácticas, representaciones y categorías (pp. 79-109). Quito: FLACSO.

Tijoux, M. E. (2011). Trayectorias laborales de los inmigrantes peruanos en Chile: Estrategias de estructuración de la movilidad ocupacional ascendente. Santiago: Universidad Alberto Hurtado.

Yuval-Davis, N. (2004). Género y nación. Lima: Flora Tristán.

\section{Notas}

* Artículo de investigación.

i Entenderemos el género desde planteamientos feministas (Butler, 2002, 2007; Scott, 2011; Crenshaw, 1989) como una construcción social performativa, es decir, producida a través de actos reiterados en el tiempo que tienen como efecto la naturalización de comportamientos, cuerpos y posiciones sociales femeninas o masculinas. 